\title{
Inference making while reading narrative and expository texts: An ERP study
}

\author{
Luciane Baretta ${ }^{1}$, Lêda Maria Braga Tomitch², Nicolas MacNair ${ }^{3}$, Vanessa Kwan Lim³ and Karen \\ Elizabeth Waldie ${ }^{3}$
}

1 Universidade do Oeste de Santa Catarina, Brazil

2 Universidade Federal de Santa Catarina, Brazil

3 University of Auckland, New Zealand

\begin{abstract}
Much of the recent research on discourse comprehension has centered on the readers' ability to construct coherent mental representations of texts. In order to form a unified representation of a given text, a reader must be able to join the information presented in the text with his/her background knowledge to construe the meaning that may not be explicitly stated, through the generation of inferences. In this study, the process of inference making by native speakers of English while reading two different types of text was investigated using electroencephalography (EEG). Subjects read narrative and expository paragraphs, and judged the plausibility of the final sentence of each four-sentence long paragraph by reference to the previous information. The analysis of data focused on the N400 component and on accuracy of behavioral responses. N400 amplitudes revealed that exposition was more demanding than narration in terms of semantic processing, whereas the behavioral data showed that subjects were more prone to generate inferences when reading exposition. Overall, this study suggests that these two types of text are processed differently by the brain, as revealed by the changes in the N400 component across the last sentences of the paragraphs. Keywords: inference making, narration, EEG, ERPs, N400.
\end{abstract}

Received 20 October 2009; received in revised form 14 December 2009; accepted 15 December 2009. Available on line 29 December 2009.

\section{Introduction}

Research on inference making has been one of the central issues in psycholinguistics, text linguistics and discourse psychology for the past thirty years. In the specific case of reading, text comprehension researchers have been challenged in trying to answer which inferences readers can be counted on to reliably draw. This is mostly guided by the fact that, unlike listening to

Luciane Baretta, Grupo de Pesquisa Educação, Comunicação e Novas Tecnologias, ÁreadeCiências Humanase Sociais, Universidade do Oeste de Santa Catarina, Brazil. Lêda Maria Braga Tomitch, Núcleo de Estudos em Leitura, Programa de Pós-Graduação em Letras/Inglês, Universidade Federal de Santa Catarina, Brazil. Nicolas MacNair, Research Centre for Cognitive Neuroscience, Department of Psychology, University of Auckland, Auckland, New Zealand. Karen E. Waldie, Research Centre for Cognitive Neuroscience, Department of Psychology, University of Auckland, Auckland, New Zealand. Vanessa K. Lim, Research Centre for Cognitive Neuroscience, Department of Psychology, University of Auckland, Auckland, New Zealand. Correspondence regarding this article should be directed to: Luciane Baretta, Universidade do Oeste de Santa Catarina, Avenida Getúlio Vargas, 2125. Curso de Letras, ACHS, 89600-000, Joaçaba, SC/Brazil. E-mail: barettaluciane@gmail.com someone talk, readers cannot ask for clarifications and the message may not be correctly understood. Although the matter of inference generation is still in its infancy, there are a considerable number of paradigms (cued recall, question-answering, gaze duration, naming, lexical decision, and modified Stroop task, among others) and display times (during, immediately after, or long after reading) that have been used to study the process of inference making. More recently, researchers have employed electrophysiological techniques, such as electroencephalogram (EEG), to understand how the brain processes discourse and, consequently, how inferences are generated. The purpose of this study was to investigate this crucial aspect of discourse comprehension: the process of inference making, through the use of EEG.

\section{Inference and reading comprehension}

What is inferencing? At a general level, it may be equated to reasoning since it is a cognitive process that is part of our everyday experiences (Winne, Graham, \& Prock, 1993). For example, when a new computer program is used for the first time, one has to activate from long-term memory the steps involved in operating 
a computer and infer differences and similarities between the new program and what is known about other programs. Similarly, when we have friends over and have to make coffee for more people than the usual, we are able to infer that as we need more water, we will need to add more coffee; otherwise it will be too weak. These simple examples demonstrate that the process of inference-making is not an obscure, difficult task that is only contingent upon the acts of reading; in fact, it is part of our everyday routine.

In the realms of language comprehension, the term refers to "any information about events, relations, and so on that the reader adds to the information that is explicitly presented" in discourse (van den Broek, Risden, \& Husebye-Hartmann, 1995: 353). For instance, when reading: Jane left early for the party. She spent an hour shopping at the mall. (from Shears \& Chiarello, 2004), most readers are able to infer that Jane decided to leave earlier to get something for the party, which is possibly a birthday gift. The ability to draw inferences in reading comprehension is, therefore, a constructive cognitive process in which the reader strives for meaning and expands knowledge by formulating and evaluating hypotheses about the information in the text.

The act of inferencing is paramount for text comprehension because it makes possible for readers to establish a representation of the meaning of the text in memory on the basis of its coherence relations and the readers' general knowledge (Gernsbacher, 1990, 1997; Halldorson \& Singer, 2002; Linderholm, 2002; Long, Oppy, \& Seely, 1997; Magliano, Trabasso, \& Graesser, 1999; Noordmann \& Vonk, 1992; Trabasso \& Magliano, 1996; van Dijk \& Kintsch, 1983). Hence, if readers fail to execute processes that integrate different portions of a text and to make inferences based on their general knowledge to elaborate on the text representation, they may fail to understand the text and have difficulties in remembering it (Horiba, 2000; Linderholm \& van den Broek, 2002; Long et al., 1997; Trabasso \& Suh, 1993; Trabasso, Suh, Payton, \& Jain, 1995).

There has been considerable controversy among researchers over matters of inference generation. Questions regarding the types and frequency of inferences that are generated online or during a later task, the sources of information that are necessary to elicit them, and the set of cognitive processes that are involved during their generation, are some of the topics that have stimulated discourse psychologists and linguists to understand how readers construct situation models ${ }^{1}$.

Inference generation studies that used the narrative type of text as stimulus, i.e., stories with beginning, middle and end, character(s), plot and setting, abound in the literature (Beeman, 1993; Lehman-Blake \& Tompkins, 2001; Magliano et al., 1999; Mason \& Just, 2004; Singer, Andrusiak, Reisorf, \& Black, 1992; Trabasso \& Magliano, 1996; Virtue, Haberman, Clancy, Parrish, \& Beeman, 2006, among others). Little is known about the process of inference making in expository texts, i.e., a unified piece of writing aiming at presenting information in a logical sequence relation of facts (Winter, 1994). Moreover, from the few studies that considered exposition to investigate inference making (e.g., Linderholm \& van den Broek, 2002), there are even fewer that have compared the effects that narration and exposition have on the generation of inferred information and the patterns of brain activation that accompany each type of processing. Therefore, there is a need to investigate to what extent different types of text influence cognitive processing across the two cerebral hemispheres. For the process of inference making, clinical and brain lesion literature and, more recently, neuroimaging evidence, suggest that some areas of the right hemisphere (e.g., inferior and middle temporal sulcus, inferior frontal gyrus and inferior parietal areas) are particularly involved in the process of inference generation (Mason \& Just, 2004; St. George, Kutas, Martines, \& Sereno, 1999; Tomitch, Newman, Carpenter, \& Just, 2008). The present study further investigated the process of inference making, using EEG, in order to verify the differences in right and left brain processing while subjects read two different types of texts, namely exposition and narration. The focus of analysis was on both behavioral (accuracy of responses) and EEG (amplitude of brain waves generated during reading) data. It was hypothesized that readers would have more accurate responses when judging the suitability/unsuitability of inferences and that they would generate inferences more easily (as revealed by small N400 amplitudes) in the narrative type of text.

\section{EEG and the N400 component}

There is a variety of non-invasive tools available for researchers to investigate the neural correlates of brain functioning. These methods can be categorized according to the type of information on brain activity they provide: high spatial or temporal resolution (OCDE, 2003). The N400 effect (incongruent minus congruent) is probably one of the most investigated in language research since the publication of the seminal article by Kutas and Hillyard in 1980 on semantic processing of written sentences. Also employed to investigate semantic processing is the N400 component, which

Note (1) - Current theories of text comprehension assume three levels of representation of the text: the surface level, i.e., the literal information; the semantic level, i.e., the construction of local and global sequences of propositions; and the situation model, which implies the integration of the reader's prior knowledge with the textual information (see for example Kintsch, 1998; Kintsch \& van Dijk, 1978; van Dijk \& Kinstch, 1983). 
is a negative wave, peaking at about $400 \mathrm{msec}$ and is associated with readers' difficulty in integrating a lexical element in the preceding context. Given the fact that all words elicit an N400 (Kutas \& Schmitt, 2003), this is a sensitive measure for meaning access and integration, being therefore a useful index for analyzing discourse processing (Kutas \& Hillyard, 1984; Raney, 1993; Salmon \& Pratt, 2002; van Berkum, Hagoort \& Brown, 1999) and more specifically, the process of inference making (St. George, Mannes, \& Hoffmann, 1997).

\section{Method}

\section{Participants}

Sixteen male, right-handed paid subjects participated in this study. All subjects were native speakers of English and students at the University of Auckland, Auckland, New Zealand. Their average age was 22 years (range 1831 ). The subjects had normal visual acuity with no known language impairment or any neurological or psychiatric disorders. Each subject read and signed a consent form approved by the University of Auckland Human Participants Ethics Committee (ref. 2007/104). Data of two of the subjects were eliminated from the analysis due to technical problems in segmenting their data. Therefore, all analyses were carried out with fourteen subjects.

\section{Apparatus}

The EEG was recorded continuously with a sampling rate of $1000 \mathrm{~Hz}$, using an Electrical Geodesics Inc. (EGI) 128-channel Ag/AgCl electrode net (Electrical Geodesics Inc., Eugene, OR, USA). All the electrodes were referred to a common vertex $(\mathrm{Cz})$ on line and later re-referenced to an average of the left and right mastoid sites. Recordings that were contaminated by excessive eye blinks were rejected (rejection criterion of $70 \mu \mathrm{V}$ in eye channels). Automatic eye-movement correction was conducted, according to the methods used by Jervis, Nichols, Allen, Hudson, \& Johnson (1985). Impedance of electrodes was kept below $40 \mathrm{k} \Omega$. Thirteen recording sites were considered in this study; the selection of electrodes was based on previous EEG research on sentence- and discourse-level (Salmon \& Pratt, 2002; St. George et al., 1997; van Berkum et al., 1999).

The stimuli consisted of 30 narrative paragraphs that were based on a previous study conducted by St. George (1995) ${ }^{2}$ and 30 original expository paragraphs that were extracted from naturally occurring texts in English and adapted to satisfy the requirements of the experiment. All the paragraphs were four-sentence long and the length of the sentences ranged from 4 to 14 words for the narratives (mean $=8.4$ words) and from 5 to 14 words for the expository paragraphs (mean $=8.7$ words). Each paragraph addressed a different situation or fact and contained information related to general knowledge, i.e., education, health, technology, hobbies, leisure, work life, everyday routine and so on.

The original expository paragraphs were written and adapted so that they represented a complete and unified piece of writing in terms of structure and texture(Halliday \& Hasan, 1990). The paragraphs were organized on the basis of a logical sequence relation of facts (Winter, 1994), so that the information presented in each sentence was interrelated so as to lead to a plausible conclusion, i.e., a deductive or causal sequence for each paragraph. Similar to St. George's narrative paragraphs, the thirty expository paragraphs had a bridging/congruent and a no-inference/incongruent condition version (30 x 2 $=60$ expository paragraphs). The bridging condition refers to the condition that emerges when the first three sentences suggested/led to the inference stated in the fourth sentence. The incongruent condition illustrates the paragraphs that, although may sound coherent in the first three sentences, do not lead to the inference stated in the fourth sentence, causing surprise in the reader when reading the final sentence. The first and the last sentence were the same for both conditions of a particular paragraph, although subjects were presented to only one of the two versions of each paragraph.

The first sentence presented a fact that contextualized the paragraph (e.g., "Alcohol and antibiotics are not a good combination.") and the fourth sentence explicitly stated the conclusion/inference (e.g., "Alcohol should be avoided when on antibiotics."). In the bridging condition, the second sentence presented information that, connected to the previous sentence, suggested an inference (e.g., "Apparently, alcohol lessens the effects of the medicine."). The third sentence presented supporting evidence or added information to the generation of an inference (e.g., "People take longer to recover when they drink during treatment."). In the incongruent condition, the second and the third sentences were designed to maintain coherence (in the first three sentences) but to keep the reader from making an inference (e.g., "Doctors recommend eating heaps of yoghurt while on antibiotics. Some antibiotics destroy the flora in our gut.").

\section{Procedure}

Subjects were tested individually in one experimental session lasting approximately 90 minutes. Subjects received an explanation about the steps involved in the whole experiment, read and signed their informed consents. After the set-up of the EEG net, subjects were tested in an electrically shielded chamber. They were seated on a comfortable chair, approximately $57 \mathrm{~cm}$ in front of a VGA monitor, and were instructed to read 60 four-sentence long paragraphs for comprehension and judge whether the last sentence of each paragraph was 
a suitable conclusion for that paragraph, by pressing " 1 " or " 2 " after the prompt "Agree $=1$ / Disagree = 2" displayed on the screen. Subjects were told that they could control the initiation of each paragraph by pressing any key on the keyboard. They were instructed not to blink excessively, nor move their heads during words presentation; they were free to rest their eyes or move their head during the breaks between paragraphs.

The paragraphs were presented word by word in black lowercase Arial letters (the first letter of each sentence was presented in capital letter) against a white background, in the center of the computer screen. The words were displayed for a duration of 300msec/word with a 300/msec interword interval plus $8 / \mathrm{msec}$ for screen refresh (stimulus onset asynchrony $=608 \mathrm{msec}$ ). Subjects received practice before the actual experiment and the trials were presented in two blocks with 30 paragraphs each (first block: 30 narrative paragraphs $\mathrm{x} 2$ types of inference; second block: 30 expository paragraphs $\mathrm{x} 2$ types of inference), with a break of 3 to 5 minutes between the trials. Each block lasted approximately 15 minutes. Each subject read a set of 60 paragraphs. For each type of text, there were 15 paragraphs for the bridging condition and 15 paragraphs for the incongruent condition. Two sets of 60 paragraphs (15 paragraphs x 2 types of inference x 2 types of text) were organized so that both types of texts were represented equally across the bridging and the control conditions. After reading each paragraph, subjects had to answer by typing " 1 ” or " 2 " whether they agreed (1) or disagreed (2) that the last sentence of the paragraph was a suitable conclusion of it.

\section{Data analysis}

Recordings for each participant were segmented offline into epochs with a pre-stimulus baseline of $100 \mathrm{msec}$ and a post-stimulus of $600 \mathrm{msec}$. The recordings were averaged across all trials per condition, generating averaged waveforms of the words presented in each paragraph type, for each electrode site, for each subject. The data from the paragraphs were sorted as Text Type (narrative, expository text), Paragraph Type (bridging inference, no-inference) and Word Type (content, function ${ }^{3}$ ) for both the third and fourth sentences separately.

All the data were bandpass filtered using a bidirectional 3 pole Butterworth filter (Alarcon, Guy, \& Binnie, 2000) between 0.1 and $30 \mathrm{~Hz}$. Repeatedmeasures ANOVAS used the most negative peak values computed for each subject in the typical N400 window of 300 to $500 \mathrm{msec}$, for both third and fourth sentences.
The behavioral data, which were recorded simultaneously to EEG acquisitions, with the aid of EPrime program, were scored according to the subjects' responses in relation to their judgment of the paragraphs (suitable conclusion/agree or not suitable conclusion/ disagree) and sorted according to each type of paragraph, i.e., exposition bridging, exposition no-inference, narrative bridging, narrative no-inference ${ }^{4}$.

\section{Results}

\section{Behavioral data}

The behavioral data correspond to the subjects' judgment in relation to the suitability of the last sentence, i.e., whether it was a plausible conclusion according to the information presented in the three previous sentences, for each of the 60 paragraphs.

A two-way ANOVA, with type of inference (bridging, no-inference) and text type (expository, narrative) as repeated measures revealed a significant main effect of text type $(\mathrm{F}(1,13)=21.317, p=<.001)$. Subjects were better at drawing bridging inferences while reading expository paragraphs (mean $=13.0$, out of 15 paragraphs) than when reading narrative paragraphs (mean $=9.29$, out of 15 paragraphs). The main effect of type of inference approached significance $(\mathrm{F}(1,13)=4.613, p=.051)$. Subjects were better at judging the unsuitability of the last sentences (mean $=12.32$, out of 15 paragraphs) than the congruency of the last sentences of the paragraphs (mean $=11.14$, out of 15 paragraphs). The interaction between text type and type of inference did not reach significance.

\section{EEG Data}

The N400 data generated by the words in the final and third sentences of each of the paragraphs were analyzed according to the 300-500 msec time-window, typical of the N400 component. The values for the N400 were calculated by locating the maximum negative values in microvolts $(\mu \mathrm{V})$ between 300 and 500 msec for each of the conditions, for each subject.

\section{N400s: final sentence}

Grand averages for the most relevant electrode sites (midline central, right/left central) for paragraph types in the final sentence (exposition bridging, exposition no-inference, narrative bridging, narrative no-inference) are displayed in Figure 1 below. In

Note (3) - Following St George et al.’s (1997) analysis, this study discriminated between content and function words due to the fact that they elicit different ERPs. (Kutas \& van Petten, 1994). In this study, content (or major and also, open) words classification consists of nouns, verbs, most adjectives and the -ly ending adverbs. Function (or minor and also, closed) words include auxiliary verbs (was), articles, complementizers (which), conjunctions, sentence connectors, interrogatives, verb particles, prepositions, pronouns and some adjectives and adverbs.

Note (4) - Although suggested by one of the anonymous reviewers, reaction time (RT) responses were not considered in this study because our primary interest in including behavioral responses was to ascertain that our subjects would process all the paragraphs and, therefore, generate good EEG signals; the decision of including behavioral data in the analysis was for descriptive purposes only. 
NARRATIVE TEXT

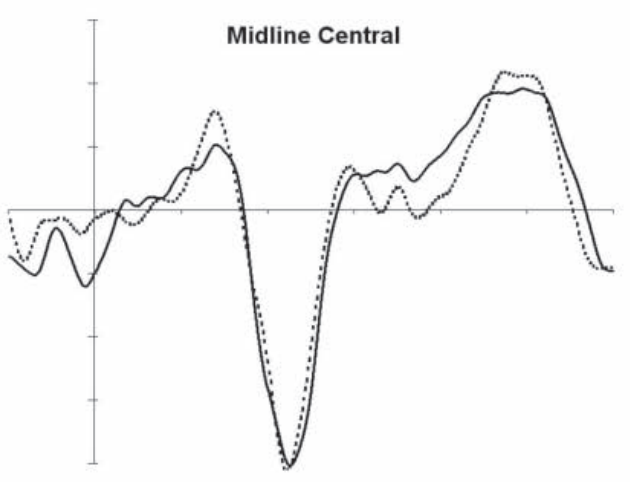

Left Central

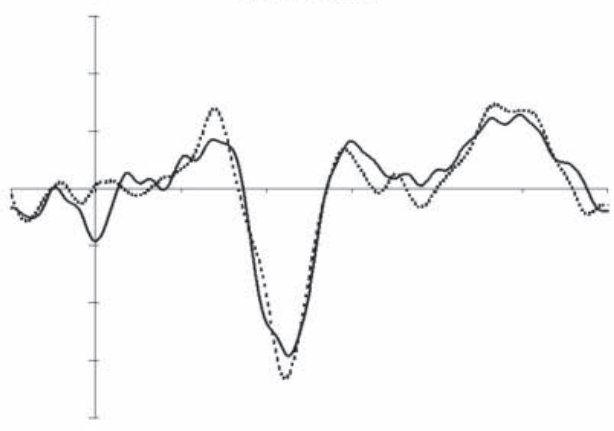

Right Central
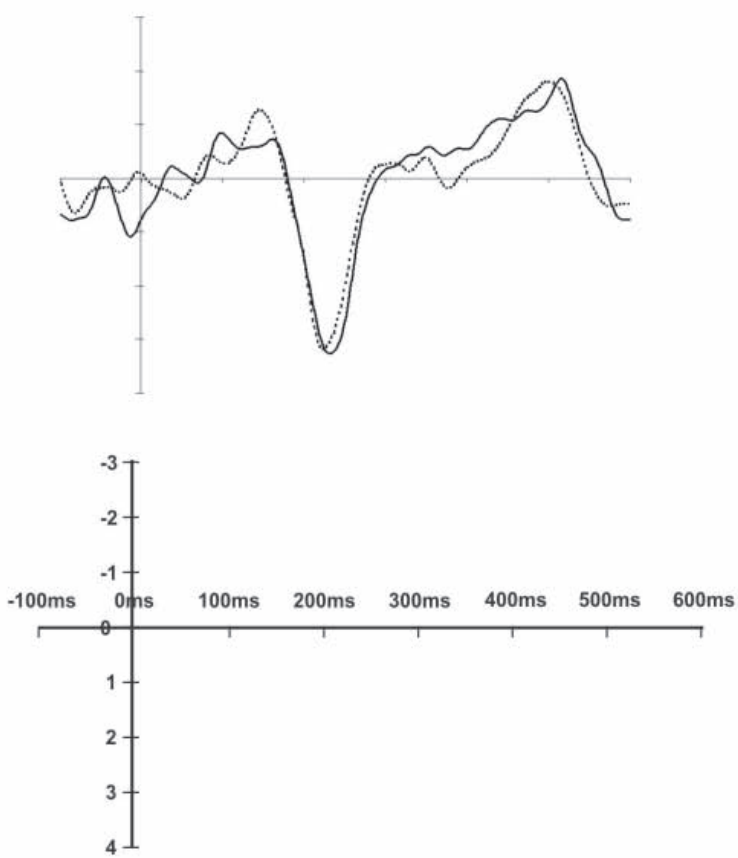

\section{EXPOSITORY TEXT}
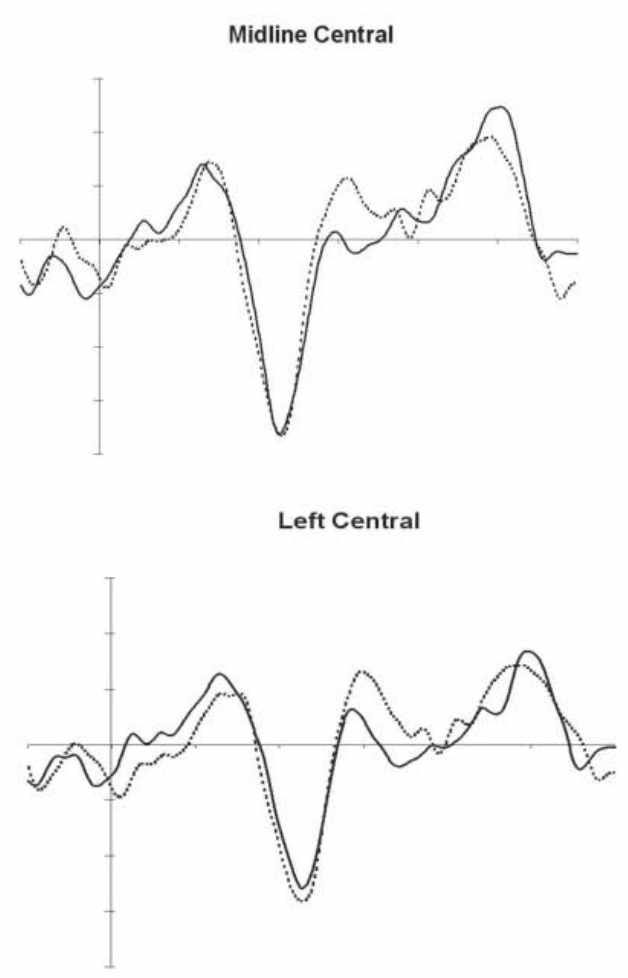

Right Central

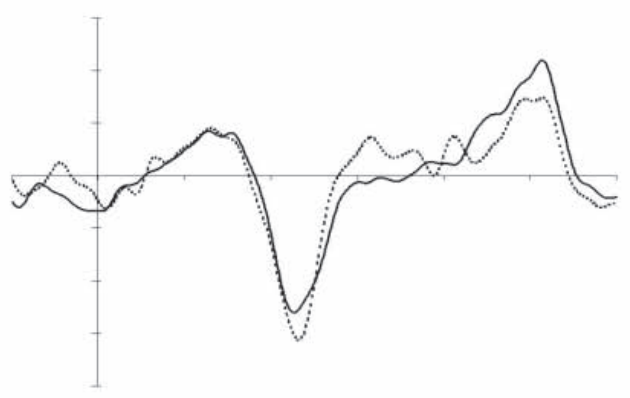

Bridging inference

Figure 1. Average waveforms for the most relevant electrodes for the $4^{\text {th }}$ sentence for both narrative and expository texts. Negativity is plotted up. 

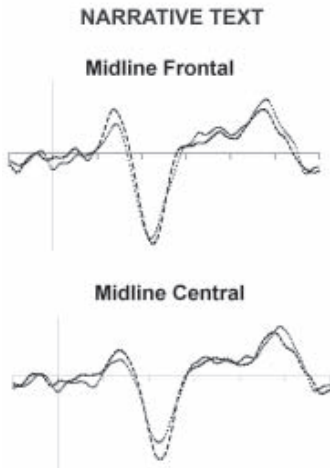

Midline Parieta

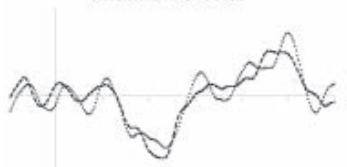

Left Frontal

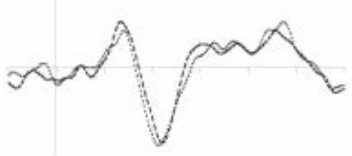

Left Central

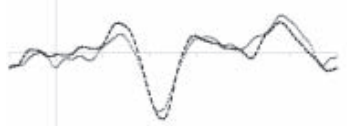

EXPOSITORY TEXT

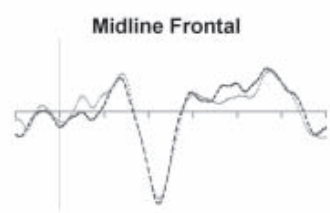

Midline Central

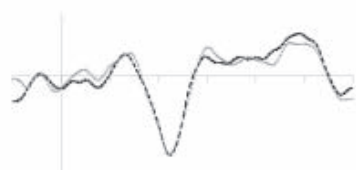

Midline Parietal

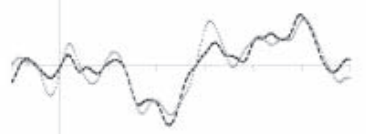

Left Frontal

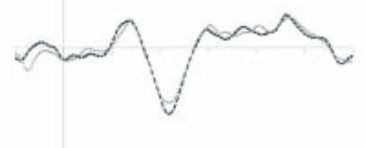

Left Central

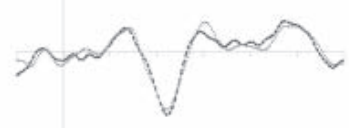

Figure 2. Average waveforms for the third sentence for both narrative and expository texts. The electrodes are referred to their location and correspond respectively to electrodes (top to bottom): 11, 129, 62, 33, 36. Negativity is plotted up.

accordance with other studies using visual words (Coulson \& Van Petten, 2002), the ERPs in this study are characterized by N100 peaks at frontal and central sites and a P2 component identified at all sites, except the occipital. These components are followed by N400s, also identified at most sites.

A two-way repeated-measure ANOVA with paragraph type (exposition bridging, exposition noinference, narrative bridging, narrative no-inference) and electrode sites (13 levels) was conducted to verify possible amplitude differences between paragraph types. The analysis showed that there is a significant main effect of electrode sites $(F(12,156)=14.102, p$ $=<.001)$, with the maximal amplitude measured over the central site $(\mathrm{Cz}$, means $=-3.12 \mu \mathrm{V})$, which was significantly different from amplitudes measured at all other sites $(p<.05)$, except the midline $\mathrm{Fz}$ and $\mathrm{Pz}$ and the right occipital site $(p>.05)$. No other main or interaction effects were found.
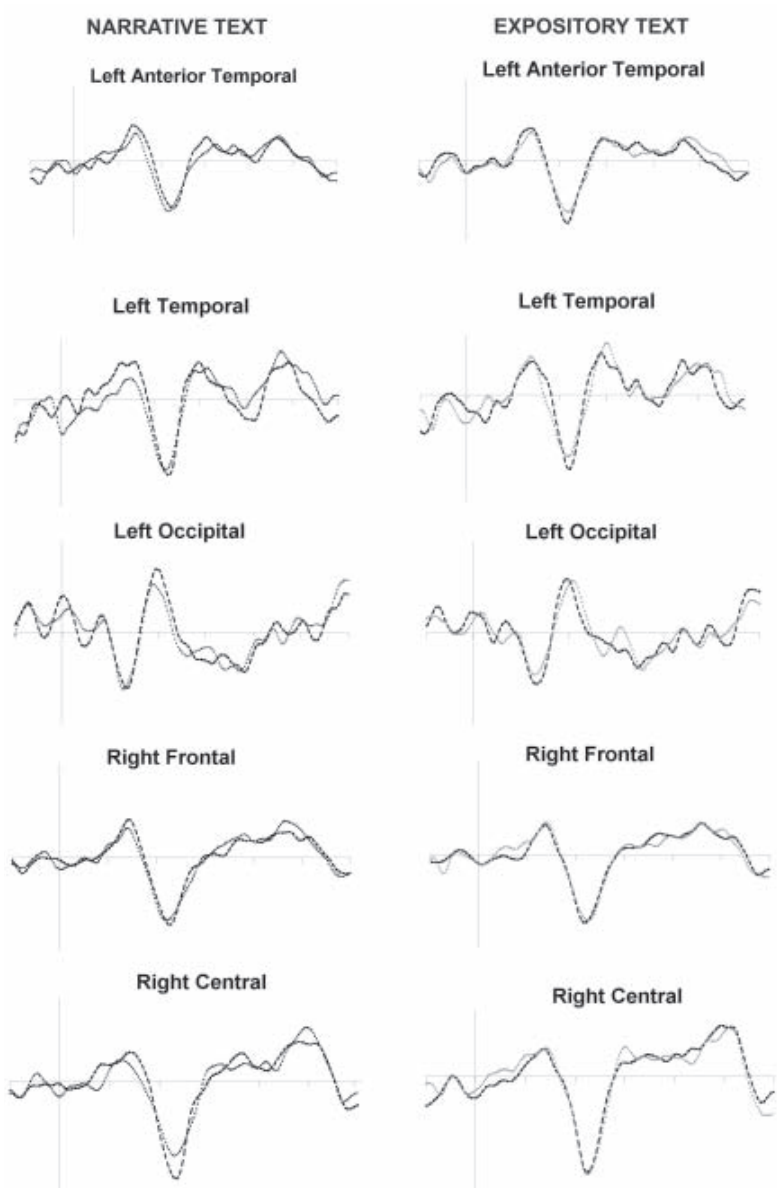

Figure 3. Average waveforms for the third sentence for both narrative and expository texts. The electrodes are referred to their location and correspond respectively to electrodes (top to bottom): 39, 46, 65, 122, 104. Negativity is plotted up.

A three-way repeated-measures ANOVA with type of word (content, function), text type (expository, narrative) and scalp area (midline, RH, LH) as factors was conducted to investigate possible amplitude differences between type of word and text type at three scalp areas, mainly RH and LH. The 13 electrodes considered in this study were grouped according to their position on the scalp: midline position (Fz, Cz, Pz); RH: (F8, C4, electrodes 115, 102, 90) and LH (F7, C3, electrodes 39, $46,65)$. The analysis revealed a significant main effect of scalp area $(\mathrm{F}(2,26)=48.864, p=<.001)$. No other significant main or interaction effects were found. For the main effect of scalp area, N400 peak values were larger in the midline area (means $=-2.74 \mu \mathrm{V}$ ), followed by the RH (means $=-2.0 \mu \mathrm{V}$ ) and by the LH (means = $1.82 \mu \mathrm{V}$ ) in third. Pair-wise comparisons revealed there was a significant difference in the N400 amplitudes between midline area and $\mathrm{RH}(p<.001)$ and midline area and $\mathrm{LH}(p<.001)$ but not between $\mathrm{RH}$ and $\mathrm{LH}^{5}$.

Note (5) - Even though a 128 channel system was used, topographical analysis was not conducted in this research, since the thirteen electrodes used captured the region of interest sufficiently and the amplitude of the components was our primary interest. Furthermore, significant changes in topography were not expected, based on earlier work. 


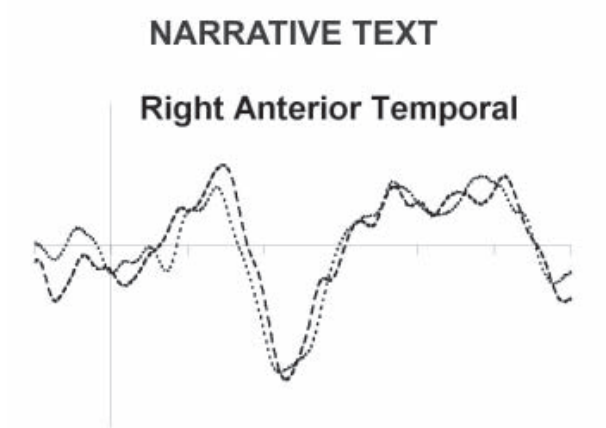

Right Temporal

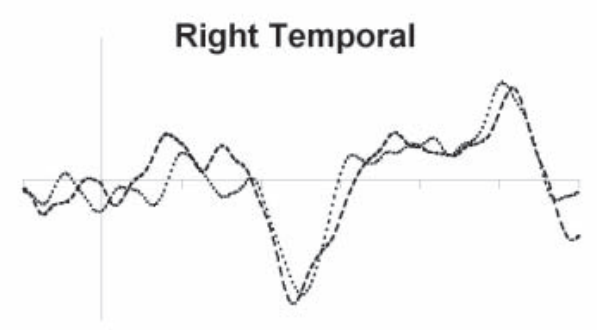

Right Occipital
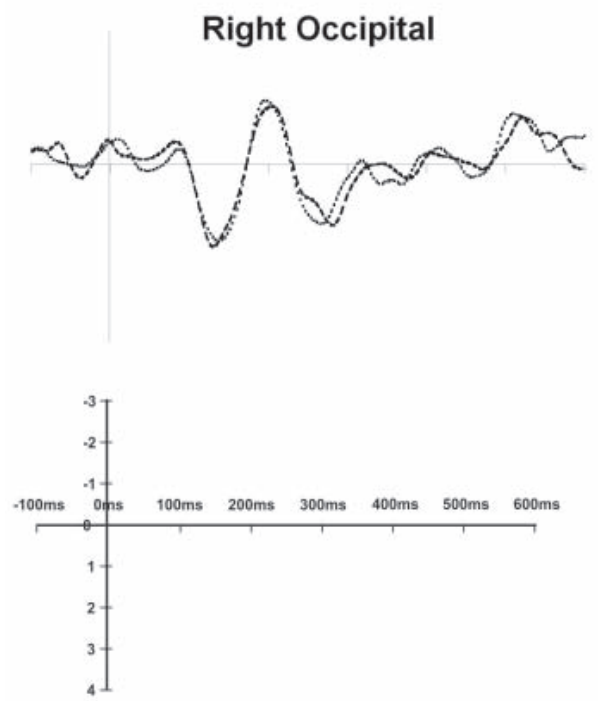

EXPOSITORY TEXT

Right Anterior Temporal

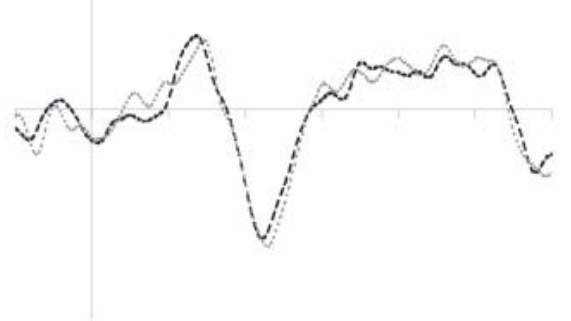

Right Temporal

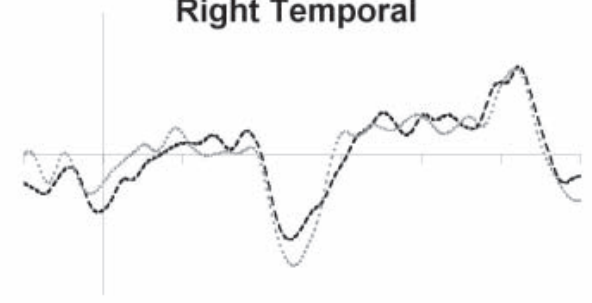

Right Occipital

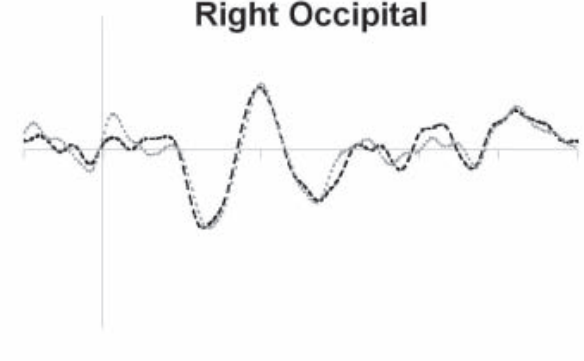

Figure 4. Average waveforms for the third sentence for both narrative and expository texts. The electrodes are referred to their location and correspond respectively to electrodes (top to bottom):115, 102, 90. Negativity is plotted up.

\section{N400s: sentence three}

A two-way repeated-measures ANOVA with paragraph type (exposition bridging, exposition noinference, narrative bridging, narrative no-inference) and electrode sites (13 levels) was conducted to verify possible amplitude differences between paragraph types in sentence three. The analysis showed significant main effects of electrode sites $(\mathrm{F}(12,156)=17.591, p=<$ $.001)$ and paragraph type $(\mathrm{F}(3,39)=4.860, p=<.01)$. In relation to the main effect of electrode sites, maximal amplitudes were measured over the central site $(\mathrm{Cz}$, mean $=-2,96 \mu \mathrm{V})$ and they were significantly different from amplitudes measured at all other sites ( $p<.03$ ), except the midline Fz and Pz. Pair-wise comparisons for the main effect of paragraph type showed a significant difference between exposition bridging (more negative) and narrative bridging conditions ( $p=<.05$ ) (see Figures 2, 3 and 4). No other significant comparisons were found.

\section{Discussion}

The behavioral results revealed that participants performed significantly better when reading exposition than when reading narrative texts. That is, they generated bridging inferences more easily and were better at judging the unsuitability of the last sentence in the expository paragraphs. These findings were somewhat surprising, since there is substantial evidence that readers generate considerably more inferences when reading narratives (Graesser \& Kreuz, 1993; Trabasso 
\& Magliano, 1996). Horiba (2000), however, also observed that readers generated backward connecting inferences, i.e., bridging inferences, more frequently for essays than for stories. The author reported that the type of expository text used in that study - newspaper essay was less demanding than the typical expository passages that have been used in former research with exposition. This also seems to be the case in the present study, since the expository paragraphs were extracted from authentic material and adapted so that they represented a complete and unified piece of writing. The paragraphs addressed topics related to general knowledge and were not aimed at presenting information which readers were expected to acquire as knowledge. In fact, most of the studies that have investigated the process of inference making in exposition have worked with quite difficult or unfamiliar science topics, such as chlorine compounds and propellants (Noordman, Vonk, \& Kempf, 1992), nuclear power and star explosions (Millis \& Graesser, 1994), among others. Therefore, given the fact that the expository paragraphs of this study approached general topics and were organized on the basis of a logical sequence relation of facts, which were interrelated across sentences, it is possible that readers processed the informational structure quite easily. Moreover, all subjects were university students and, as such, are often required to read more complex expository texts. Hence, it is possible that the process of reading expository paragraphs was somewhat similar to the flow of reading normally associated with narratives, which are generally processed easily by readers.

Regarding EEG data, there was no significant difference between bridging (congruent) and noinference (incongruent) conditions in the fourth sentence. It was expected that the subjects' reading process would have varied considerably in terms of N400 amplitudes across these two conditions. That is, the no-inference condition should have elicited larger N400s for its unexpected or incoherent conclusion, e.g., Gum chewing increases cognitive capacities, in a context stating that Repetitive chewing motion stimulates, besides insulin going to the brain, salivary flow and that it is a combination of water-soluble ingredients. The bridging condition, on the other hand, given that the conclusion of the paragraph is coherent to the previous context, i.e., Repetitive chewing motion stimulates insulin going to the brain, as well as thinking and memory, should have elicited a smaller N400 peak.

The results are therefore contrary to those presented by St. George et al. (1997). In that study, the authors investigated whether individual differences influenced the generation of bridging and elaborative inferences, by asking subjects to read paragraphs for later recall. The most significant differences were observed between bridging and no-inference conditions, contrary to the present study, where differences between these two conditions were small and similar across the two text types investigated. One may speculate that our behavioral task and the reading instructions - read to decide if the last sentence is suitable to the paragraph - may have influenced the way readers approached the text. If so, this may have generated different results from earlier studies that investigated the effect of different tasks on reader's performance (Calvo, Castillo, \& Schmalhofer, 2006; Linderholm \& van den Broek, 2002; Narvaez, van den Broek, \& Ruiz, 1999). This is an issue that deserves further investigation, with a larger number of subjects, before any assertions can be made.

The main objective of the current study was to investigate whether different types of text would influence the process of bridging inferences. The behavioral results showed that subjects had significantly better performance generating bridging inferences and in judging the unsuitability of the incongruent condition when reading the expository type of text. Thus, the larger N400 components in the bridging congruent expository sentences found in the third sentence is consistent with the better accuracy results in the behavioral measure. Although there was not a significant difference in the N400 amplitudes in the fourth sentence (where subjects read the explicit inference) between exposition and narration, there was a significant difference in the third sentence (where supporting information was given so as to elicit the inference explicitly stated in the next sentence). This finding appears to signal that, since subjects were already in the process of generating inferences while reading sentences two and three, they may have anticipated the outcome of the paragraphs by sentence three. This would explain the lack of significant difference in the N400s between exposition and narration in sentence four.

Therefore, the EEG data suggest that judging the plausibility of the expository sentences required more cognitive processing than narrative text and that this effect was present before the final sentence of the paragraphs.

\section{Final remarks}

The present study intended to contribute to a better understanding of the process of inference making across different types of text, by investigating, by means of the use of EEG, how readers construct meaning while reading a text. The decision for working with narrative and expository type of texts came from the discourse comprehension literature, which abounds with empirical evidence concerning the cognitive aspects involved in the comprehension of stories, showing, however, a paucity of studies that involve the expository type of text as stimulus. There is even less knowledge about the comparison between narrative and exposition, possibly because the conclusion is taken for granted, i.e., that narratives are easier to understand than expository texts. 
Despite some limitations, this study suggests that the two types of text investigated are indeed processed differently by the brain, as demonstrated by the differences in the N400 component particularly found in sentence three.

\section{Acknowledgments}

This research was partially supported by Coordenação de Aperfeiçoamento de Pessoal de Nível Superior, CAPES, Brazil, process number 0169/07-2) granted to the first author, as part of her PhD studies.

\section{References}

Alarcon, G., Guy, C.N., \& Binnie, C.D. (2000). A simple algorithm for a digital three-pole Butterworth filter of arbitrary cut-off frequency: Application to digital electroencephalography. Journal of Neuroscience Methods, 104, 35-44.

Beeman, M. (1993). Semantic processing in the right hemisphere may contribute to drawing inferences from discourse. Brain and Language, 44, 80-120.

Calvo, M.G., Castillo, D., \& Schmalhofer, F. (2006). Strategic influence on the time course of predictive inferences in reading. Memory and Cognition, 34(1), 68-77.

Coulson, S., \& van Petten, C. (2002). Conceptual integration and metaphor: An event-related potential study. Memory and Cognition, 30(6), 958-968.

Gernsbacher, A.M. (1990). Language Comprehension as Structure Building. LEA: Erlbaum, Hillsdale, N.J..

Gernsbacher, A.M. (1997). Two decades of structure building. Discourse Processes, 23, 265-304.

Graesser, A.C., \& Kreuz, R.J. (1993). A theory of inference generation during text comprehension. Discourse Processes, 16, 3-34.

Halldorson, M., \& Singer, M. (2002). Inference processes: Integrating relevant knowledge and text information. Discourse Processes, 34(2), 145-161.

Halliday, M.A.K., \& Hasan, R. (1990). Language, context, and text: Aspects of language in a social-semiotic perspective. Oxford: Oxford University Press.

Horiba, Y. (2000). Reader control in reading: Effects of language competence, text type and task. Discourse Processes, 29(3), 223-267.

Jervis, B.W., Nichols, M.R., Allen, E.M., Hudson, N.R., \& Johnson, T.E. (1985). The assessment of two methods for removing eye movement artifact from the EEG. Electroencephalography and Clinical Neurophysiology, 61, 444-452.

Kintsch, W. (1998). Comprehension: A paradigm for cognition. New York: Cambridge University Press.

Kintsch, W., \& van Dijk, T.A.(1978). Toward a model of text comprehension and production. Psychological Review, 85(5), 363-394.

Kutas, M., \& Hillyard, S.A. (1980). Reading senseless sentences: Brain potentials 513 reflect semantic incongruity. Science, 207, 203-205.

Kutas, M., \& Hillyard, S.A. (1984). Brain potentials during reading reflect word expectancy and semantic association. Nature, 307, 161-163.

Kutas, M., \& Schmitt, B.M. (2003). Language in microvolts. In: Banich, M.T., \& Mack, M. (Eds.), Mind, brain and language multidisciplinary perspectives. (pp. 171-209). Mahwah, New Jersey: Lawrence Erlbaum Associates.

Kutas, M. \& Van Petten C.K (1994). Psycholinguistics electrified: eventrelated brain potential investigations. In Gernsbacher M.A (ed.) Handbook of psycholinguistics (pp. 83-143). San Diego, CA: Academic Press.

Lehman-Blake, M., \& Tompkins, C.A. (2001). Predictive inferencing in adults with right hemisphere brain damage. Journal of Speech, Language, and Hearing Research, 44, 639-654.

Linderholm, T. (2002). Predictive inference generation as a function of working memory capacity and causal text constraints. Discourse Processes, 34(3), 259-280.

Linderholm, T., \& van den Broek. (2002). The effects of reading purpose and working memory capacity on the processing of expository text. Journal of Educational Psychology, 94(4), 778-784.

Long, D.L., Oppy, B.J., \& Seely, M.R. (1997). Individual differences in readers' sentences- and text-level representations. Journal of
Memory and Language, 36, 129-145.

Magliano, J.P., Trabasso, T., \& Graesser, A.C. (1999). Strategic processing during comprehension. Journal of Educational Psychology, 91(4), 615-629.

Mason, R.A., \& Just, M.A. (2004). How the brain processes causal inferences in text: A multiple process theory of language function in both hemispheres. Psychological Science, 15, 1-7.

Millis, K.K., \& Graesser, A.C. (1994). The time-course of constructing knowledge-based inferences for scientific texts. Journal of Memory and Language, 33, 583-599.

Narvaez, D., van Den Broek, P., \& Ruiz, A.B. (1999). The influence of reading purpose on inference generation and comprehension in reading. Journal of Educational Psychology, 91(3), 488-96.

Noordman, L.G.M., \& Vonk, W. (1992). Reader's knowledge and the control of inferences in reading. Language and Cognitive Processes, 7(3/4), 373-391.

Noordman, L., Vonk, W., \& Kempf, H. (1992). Causal inferences during reading of expository texts. Journal of Memory and Language, 31, 573-590.

OCDE - Organização de Cooperação e Desenvolvimento Econômicos. (2003). Compreendendo o Cérebro - rumo a uma nova ciência do aprendizado. São Paulo: Senac.

Raney, G.E. (1993). Monitoring changes in cognitive load during reading: An event-related brain potential and reaction time analysis. Journal of Experimental Psychology: Learning, Memory and Cognition, 19(1), 51-69.

Salmon, N., \& Pratt, H. (2002). A comparison of sentence- and discourse-level semantic processing: An ERP study. Brain and Language, 83, 367-383.

Shears, C., \& Chiarello, C. (2004). Knowledge-based inferences are not general. Discourse Processes, 38(1), 31-35.

Singer, M., Andrusiak, P., Reisdorf, P., \& Black, N. (1992). Individual differences in bridging inference processes. Memory and Cognition, 20(5), 539-548.

St. George, M. (1995). An investigation of the nature and time-course of inferences using event-related brain potentials. Unpublished doctoral dissertation. University of Delaware, Newark.

St. George, M., Kutas, M., Martinez, A., \& Sereno, M.I. (1999). Semantic integration in reading: Engagement of the right hemisphere during discourse processing. Brain, 122, 1317-1325.

St. George, M., Mannes, S., \& Hoffman, J. (1997). Individual differences in inference generation: An ERP analysis. Journal of Cognitive Neuroscience, 9(6) 776-787.

Tomitch, L. M. B., Newman, S., Carpenter, P.A., \& Just, M.A. (2008). Comprehending the topic of a paragraph: A Functional Imaging Study of a Complex Language Process. DELTA. Documentação de Estudos em Lingüística Teórica e Aplicada, 24, 175-197.

Trabasso, T., \& Magliano, J.P. (1996) Conscious understanding during comprehension. Discourse Processes, 21, 255-287.

Trabasso. T., \& Suh, S. (1993). Understanding text: Achieving explanatory coherence through on-line inferences and mental operations in working memory. Discourse Processes, 16(1-2), 3-34.

Trabasso, T., Suh, S., Payton, P., \& Jain, R. (1995) Explanatory inferences and other strategies during comprehension and their effect on recall. In: Lorch F., \& O’Brien, E. (Eds.), Sources of Coherence in Reading. (pp. 219-39). Hillsdale, New Jersey: Lawrence Erlbaum Associates.

Van Berkum, P.H., \& Brown, C.M. (1999). Semantic integration in sentences and discourse: Evidence from the N400. Journal of Cognitive Neuroscience, 11(6), 657-671.

van Den Broek, P., Risden, K., \& Husebye-Hartmann, E. (1995). The role of readers' standards for coherence in the generation of inferences during reading. In: Lorch, R.F., \& O’Brien, E. (Eds.), Sources of Coherence in Reading. (pp. 353-373). Hillsdale, New Jersey: Lawrence Erlbaum Associates.

van Dijk, T.A., \& Kintsch, W. (1983). Strategies of Discourse Comprehension. New York: Academic Press.

Virtue, S., Haberman, J., Clancy, Z., Parrish, T., \& Beeman, M. (2006). Neural activity of inferences during comprehension. Brain Research, 1084, 104-114.

Winne, P.H., Graham, L., \& Prock, L. (1993). A model of poor reader's text-based inferencing: Effects of explanatory feedback. Reading Research Quarterly, Jan-Mar., 28.

Winter, E. (1994). Clause relations as information structure: Two basic text structures in English. In: Coulthard, M. (Ed.), Advances in Written Text Analysis. (pp. 46-68). London: Routledge. 